\title{
Regular Article \\ Genetic diversity analysis of endemic species, Garcinia cambogia Gaertn using randomly amplified Polymorphic DNA markers
}

\author{
Santosh $\mathrm{P}^{1}$ and Suresh B. Arakera ${ }^{2}$ \\ 1Division of Molecular Entomology, ICAR- National Bureau of Agricultural Insect Resources \\ (NBAIR), Bengaluru, Karnataka 560024, India \\ 2Department of Applied Genetics, Karnatak University, Dharwad-580003, Karnataka, India \\ *Corresponding author E-mail: santoshsarathy@gmail.com
}

Polymerase chain reaction based random amplified polymorphic DNA (PCR-RAPD) markers were employed to assess genetic diversity in eight Garcinia cambogia genotypes. Among the 20 random primers used in the present investigation, 9 primers showed polymorphism. A total number of 227 bands were obtained from 9 primers, out of which 225 were polymorphic, showing $99.11 \%$ polymorphism. An average of 25.22 bands per primer was scored and average number of polymorphic bands found to be 25 . The eight accessions fall into two major clusters. Cluster analysis showed that the red and yellow accessions cannot be regarded as two different varieties. The use of red and yellow fruits for commercial and medicinal purposes, respectively, is purely based on consumer preference.

Key words : Garcinia cambogia, DNA finger printing, RAPD, Genetic diversity, DNA Markers

Genetic markers are powerful tools for evolutionary and population studies, constructing genetic maps, and managing applied breeding programs. They are invaluable for examining genetic variation among and within populations, assessing levels of out crossing and inbreeding, and genetic identification of varieties or pedigrees.

Genetic polymorphism is defined as the occurrence together in the same population of more than one allele or genetic marker at the same locus with the least frequent allele or marker occurring more frequently than can be accounted for by mutation alone. Various types of genetic markers are utilized to evaluate DNA polymorphism and are generally classified as hybridization based markers and Polymerase Chain Reaction (PCR) based markers. The widely used hybridization based marker is Restriction Fragment Length Polymorphism (RFLP) and PCR based marker is Random Amplified Polymorphic DNA (RAPD) (Chaudhry 1999).

RFLP assay which detects DNA polymorphism through restriction endonuclease digestion coupled with DNA hybridization is in general, time consuming and laborious. Over the last decade, PCR technology has become a widespread research technique and has led to the 
development of several novel genetic assays based on selective amplification of DNA. The discovery that PCR with random primers can be used to amplify a set of randomly distributed loci in any genome facilitated the development of genetic markers for a variety of purposes. RAPD analysis is preferred, as it facilitates to gain large number of genetic markers that require small amount of DNA (Lassner, 1989), without the requirement for cloning, sequencing or any other form of molecular characterization of the genome of the species.

RAPD's have been used to investigate the levels of genetic diversity within and among populations, to analyze and quantify inter and intraspecific genetic variation, to assess genetic distance and to quantify genetic diversity and variation. Because of the simplicity and low cost of RAPD technique (Semagn, 2006), it has found a wide range of applications in many areas of biology. Genetic mapping, population and evolutionary genetics, developing genetic markers linked to a trait in question, and plant and animal breeding are some of them.

In recent years, more advanced marker systems such as Amplified Fragment Length Polymorphisms (AFLPs), Sequence Tagged Sites (STSs), Single Nucleotide Polymorphisms (SNPs), Simple Sequence Repeats (SSRs) or microsatellites, InterSimple Sequence Repeats (ISSRs), Sequence Characterized Regions (SCARs), Cleaved Amplified Polymorphic Sequences (CAPSs), Expressed Sequence Tags (ESTs), and Diversity Arrays Technology (DArT) have been used to analyse genetic diversity between various plant populations. Random Amplified Polymorphic DNA is the most commonly preferred technique to study the genetic diversity among different populations. Various such examples can be cited (Hiremath, 2004).

Dioecious species are generally characterized by high levels of genetic diversity; and mangosteen is unusual in that phenotypic differences are uncommon. Most of the trees found are female, since the seeds are apomictic and produce clones of the female parent. Occasional phenotypic variants observed in mangosteen plants might be a result of cross pollination from wild related species. Whether these differences could be attributed to genetic variation or were purely a consequence of being cultivated at different geographic locations, was unclear. Hence, Randomly Amplified DNA Fingerprinting (RAF) has been conducted to examine the level of genetic diversity in a population of Garcinia mangostana in Northern Queensland.

Various chemical assays have also been conducted in various species of Garcinia, especially in G. mangostana, for the detailed study of its properties. Also, in vitro techniques have been followed to regenerate plants in Garcinia species including G. indica (Sando 2010). This study has been conducted with an aim to assess the genetic diversity in Garcinia indica populations by RAPD markers and establish genetic relationships among its two different varieties. Also, a study has been made to analyse the antimicrobial activity of Garcinia leaf extracts.

\section{MATERIALS AND METHODS:}

Collection of samples:

For isolation of DNA, leaf tissue is usually preferred as it is available easily and in large amount. For the present study the 8 accessions were collected from locations such as Yellapur, Kumta, Siddapur, Dandeli, Dharwad, Arabhavi and Thalassery (Kerala). Leaves were washed with distilled water, blotted and sterilized with alcohol to kill all the surface micro organisms and processed for further isolation.

\section{RAPD PROFILING:}

Isolation of genomic DNA:

Total genomic DNA was isolated from leaf tissue according to nuclei extraction and lysis method with some modifications. 
The quality of isolated genomic DNA was checked by Agarose gel electrophoresis. $5 \mu \mathrm{l}$ of DNA was mixed with $0.5 \mu \mathrm{l}$ of $1 \mathrm{X}$ loading dye, and loaded in a slot of $0.8 \%$ agarose gel containing $0.014 \mu \mathrm{g} / \mathrm{ml}$ of Ethidium Bromide. EcoRI/HindIII $\lambda$ DNA double digest was loaded as a molecular weight marker. An intact double stranded DNA forming a thick single band of high molecular weight confirmed the presence of good quality of extracted genomic DNA.

The concentration of DNA in the extracted sample was measured using Biophotometer (Eppendorf, Germany), as a function of its optical density. The DNA samples with values between 1.6-1.8 were selected for the analysis.

\section{PCR Amplification:}

PCR reaction mixture $(19 \mu \mathrm{l}$ final volume) contained $26 \mathrm{ng}$ of DNA, $1 \mathrm{mM}$ dNTP's (Eppendorf, Germany), 10 pM Primer (Operon Technologies, Almeda) OPA and OPB series, 1X Taq polymerase buffer, 1.5 units of Taq polymerase (Enzene Biosciences, Bangalore), and $1.5 \mathrm{mM} \mathrm{MgCl}$. DNA amplification was performed in a mastercycler (Eppendorf, Germany) programmed to 1 cycle of $30 \mathrm{sec}$ at $950 \mathrm{C}$ (initial strand separation); followed by 45 cycles of $15 \mathrm{sec}$ at $950 \mathrm{C}$ (cycle denaturation), $15 \mathrm{sec}$ at $340 \mathrm{C}$ for OPA and $370 \mathrm{C}$ for OPB (annealing), $30 \mathrm{sec}$ at $72 \mathrm{OC}$ (primer extension) and $2 \mathrm{~min}$ at $720 \mathrm{C}$ (final extension).

Agarose gel Electrophoresis:

The amplification products were separated on the basis of their molecular weight, by agarose gel electrophoresis $(1.2 \%$ agarose gel) and observed under UV light. 50 bp ladder was used as molecular size marker. The gel was documented in Gel documentation unit and photographs of consistently reproducible bands were taken into consideration for data analysis.

\section{DATA ANALYSIS:}

Each amplified product was considered to be a unit character and the populations were scored for the presence (1) or absence (0) of a band. The molecular size of the amplified products were calculated from a standard curve based on the known size of DNA fragments of the $50 \mathrm{bp}$ ladder (Zymo Research). The percent disagreement between the populations was calculated based on Unweighted pair-group average. The resulting dissimilarity index was used to evaluate the relationship among various populations of this species with cluster analysis, using Unweighted pair-group average. All computations were carried out using the phylogenetic software, STATISTICA.

\section{ANTIMICROBIAL ASSAY:}

Garcinia species is well known for many properties like, anti-microbial, anti-viral, anticancer, etc. The antimicrobial trait of a plant is due to the compounds synthesized during its secondary metabolism. These products are known by their active substances, for example, the phenolic compounds which are part of the essential oils, as well as in tannins. The following study was conducted to analyse the antimicrobial activity of the leaf extract of G. indica, against a few bacterial strains namely, Klebsiella pneumoniae (109), Proteus vulgaris (1771), Pseudomonas aeruginosa (1688), and Staphylococcus aureus (737), on nutrient agar medium.

The leaf material collected was dried, powdered, sieved and used for extraction by Soxhlet method. The solvent used for extraction was methanol. According to this procedure, oil and fat from solid material are extracted by repeated washing (percolation) with an organic solvent, usually hexane or petroleum ether, under reflux in a special glassware. The extract obtained is dissolved in dimethyl formamide (DMF) in $1 \mathrm{mg} / \mathrm{ml}$ concentration, and used for the antimicrobial assay. 
Overnight grown bacterial cultures were spread plated onto nutrient agar medium to obtain uniform growth. Sterile discs containing various concentrations of the extract $(5,10,15,20$, and $25 \mu \mathrm{l})$ were placed on the agar medium. These plates were then incubated at $37{ }^{\circ} \mathrm{C}$ for 24 hours. After the incubation period, the plates were studied for the formation of plaques. The diameter of the plaques was measured and correlated with the concentration of the extract.

\section{RESULTS AND DISCUSSION}

RAPD analysis has been performed using random primers, to study the genetic diversity of this species growing under different climatic conditions. The two varieties: red-fruited and yellow-fruited, exhibit no morphological differences, except for the fruit colour and commercial value. These differences can be attributed to the variations in their genetic and chemical composition of the fruit. This intervarietal difference has been confirmed through this study. Though this species generally reproduces by apomixis, considerable genetic diversity has been observed between the plants grown under diverse climatic conditions. For the present study, twenty random primers of OPA and OPB series were screened, of which, 9 primers showed polymorphism.

Among the 20 random primers used in the present investigation, 9 primers showed polymorphism (Table 1). A total number of 227 bands were obtained from 9 primers, out of which 225 were polymorphic, showing $99.11 \%$ polymorphism. The dendrogram shows that the 8 accessions fall into two major clusters, in which cluster A consists of 3 accessions from Arabhavi and Thalassery and cluster B consists of 5 accessions from Dharwad, Siddapur, Yellapur, Kumta and Dandeli. Cluster analysis (Figure 1) showed that the red and yellow accessions cannot be reclassified as two different varieties. The use of red and yellow fruits for commercial and medicinal purposes, respectively, is purely based on consumer preference.

Table 1. Nucleotide sequences of primers used and percentage polymorphism.

\begin{tabular}{|l|l|l|l|}
\hline Primers & $\begin{array}{l}\text { No. of } \\
\text { amplified } \\
\text { products } \\
\text { (a) }\end{array}$ & $\begin{array}{l}\text { No. of } \\
\text { poly- } \\
\text { morphic } \\
\text { products } \\
\text { (b) }\end{array}$ & $\begin{array}{l}\text { \% poly- } \\
\text { morphis b/a X } \\
100\end{array}$ \\
\hline OPA-04 & 27 & 27 & 100 \\
\hline OPA-09 & 22 & 22 & 100 \\
\hline OPA-16 & 27 & 27 & 100 \\
\hline OPA-17 & 15 & 15 & 100 \\
\hline OPA-18 & 37 & 37 & 100 \\
\hline OPA-19 & 31 & 30 & 96.77 \\
\hline OPA-20 & 17 & 16 & 94.11 \\
\hline OPB-07 & 18 & 18 & 100 \\
\hline OPB-10 & 24 & 24 & 100 \\
\hline
\end{tabular}

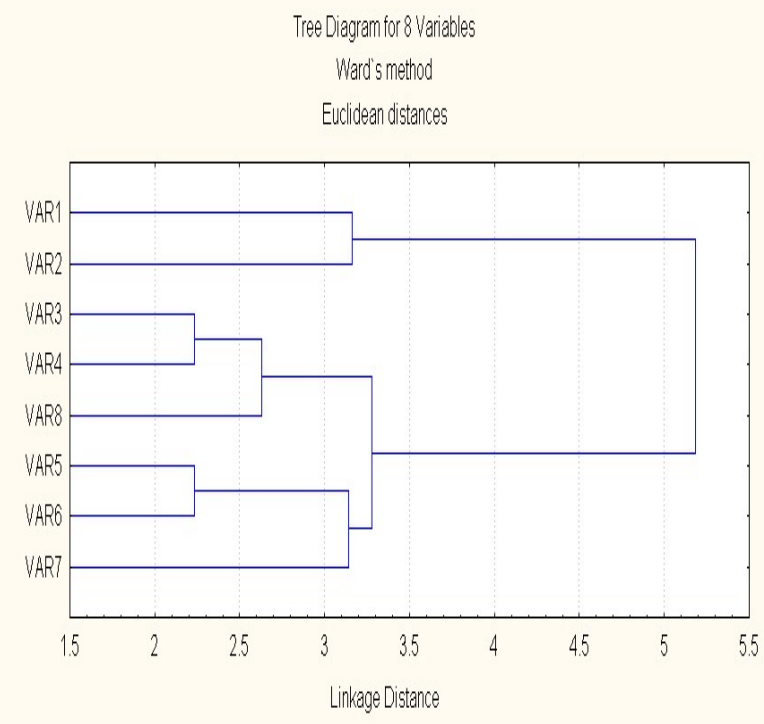

Figure 1 Dendrogram illustration of Garcinia cambogia distribution.

Hence the percentage polymorphism between all the 8 accessions has been found to be $99.11 \%$. This study has confirmed a high degree of genetic variability among different populations growing under diverse 
climatic conditions. This variation might have arisen due to the accumulation of natural mutations.

The purpose of this study was to understand the genetic diversity of $G$. cambogia accessions using RAPD technique. A better knowledge of genetic diversity and its distribution is important for its conservation. The study shows high level of genetic diversity among the accessions collected from different states of India, which was proved by the variations in their morphological characters. These results could be useful in efficient management of $G$. cambogia for their conservation and optimal utilization.

\section{References}

Chaudhry B., Yasmeen A., Husnain T. and Riazuddin S.; Mini-scale genomic DNA extraction from Cotton; Plant Mol Biol Reptr 17: 1-7, 1999.
Hiremath S. C., Nagasampige M. H. (2004): Genetic relationships among Dalbergia species revealed by PCR based DNA markers. Cytologia, 69 (2): 125-130

Lassner W. M., Peterson P., Yoder I. J. (1989); Simultaneous amplification of multiple DNA fragments by polymerase chain reaction in the analysis of transgenic plants and their progeny; Plant Mol Biol Reptr 7(2): 116-128.

Sando L., Peace C., Ramage C, Carrol B J., Drew R (2010); Assessment of genetic diversity in Australian-grown Mangosteen (Garcinia mangostana L.) and its wild relatives; ISHS Acta Horticulturae 692.

Semagn K., Bjornstad A., Ndjiondjop M. M., (2006); An overview of Molecular marker methods for plants; African Journal of Biotechnology, 5 (25): 2540-2568. 